THE UNIVERSITY OF MINNESOTA

GRADUATE SCHOOL

Report:

of

Committee on Examination

This is to certify that we the

undersigned, as a committee of the Graduate

School, have given LeRoy Michael Alois Madder

final oral examination for the degree of

Waster of Arts . We recommend that the

degree of Master of Arts be conferred

upon the candidate.

Minneapolis, Minnesota
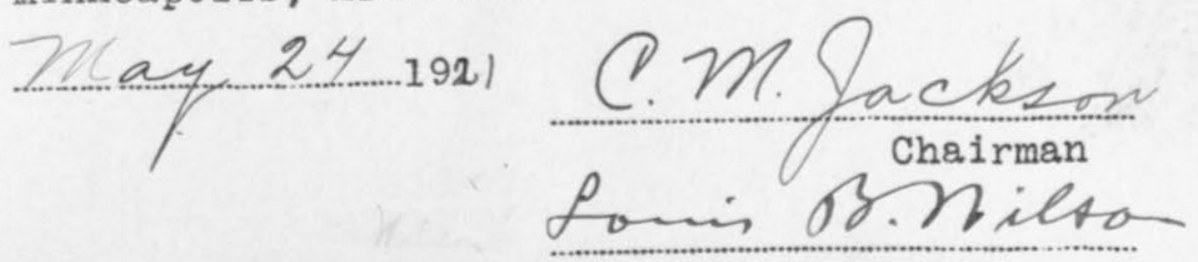

S.T. Bell.
Thomas G. Lee.

YPS Sugurith. 
THE UNIVERSITY OF MINNESOTA

GRADUATE SCHOOL

Report

of

Committee on Thesis

The undersigned, acting as a Committee of the Graduate School, have read the accompanying thesis submitted by LeRoy Michael Alois Haeder for the degree of Master of Arts.

They approve it as a thesis meeting the requirements of the Graduate School of the University of Minnesota, and recommend that it be accepted in partial fulfilment of the requirements for the degree of Master of Arts.

(2) Mackers



there 7 Welenhol 


\section{Changes in the Mammary Gland of the Albino Rat (Mus norvegicus albinus) during Iactation and Involution.}

A thesis submitted to the Faculty of the Graduate School of the University of Minnesota by

IeRoy M. A. Maeder

In partial fulfillment of the requirements for the degree of Master of Arts 
Changes in the Mammary Gland of the Albino Rat (Mus norvegicus albinus) during Iactation and Involution.

Table of Contents.

I. Introduction.

II. Iiterature.

III. Material and Methods.

IV. Observations.

A. Gross thanges.

B. Histology during Iactation.

c. Histology auring Involution.

v. Discussion.

A. Iactation.

B. Involution.

VI. Summary•

VII. Bibliography。

VIII. Explanation of Figures. 


\section{Page 3.}

\section{Introduotion.}

The primary object of this study is to determine the

anatomical changes which take place in the mammary gland of the albino rat during lactation and involution. In addition to extending our knowledge of the mammary gland in general, it is desirable to establish for this animal a norm which might serve as a basis for experimental work. A review of the literature will show that there has been very little work done on any one animal form in the nature of a detailed study of a complete series of stages during lactation and involution. Hence it was deemed desirable to work out these stages in the albino rat and thereby to complete the series of studies on the life cyele of the mammary gland of the albino rat begun by Myers ('16), who worked out the earlier stages of the development of the mammary gland up to ten weeks of age, and continued by Roberts ('21) up to the end of pregnanoy.

This investigation, like those of Myers and Roberts, was conducted in the Department of Anatomy of the University of Minnesota. The writer gratefully acknowledges his indebtedness to Dr. C. M. Jackson for the constant ald, advice, and criticism during the course of this study. He is also thankful to Dr. E. T. Bell and Dr. J. A. Myers for many helpful suggestions in this connection. 


\section{Iiterature.}

A review of the extensive literature of the research on the mammary gland in various species and a histological study of the gland during lactation in the albino rat indicate that very slight changes take place during this period. Roberta! description of the gland at the close of pregnancy in most respects applies quite well to the gland during all stages of lactation. Hence it appears unnecessary to include in this paper a review of the literature on the morphology of milk-secretion, which has already been presented in detail by Roberts ('2I).

For the period of involution of the mammary gland, however, literature is less extensive, and apparently but little detailed work has been done upon this phase of the cycle. Most statements concerning the gland during involution are very general or incidental in character. No specific data as to how involution takes place or when it is complete were found among the earlier writings. A few of the more recent investigators have considered the subject in somewhat greater detail.

Billroth ('87) claimed that upon cessation of lactation the human glandular acini collapse, though they do not disappear, but persist wi thout secreting until the next pregnanoy, then again becoming filled with cells and later again with milk. He stated that :"The connective tissue of the gland remains relaxed, and is soon transformed into fatty tissue, but it does not again take on the firm hyaline condition seen in the virgin state of the gland". Berka ("II) disagreed with this 1dea of a general persistence of the terminal acini, and thought Billroth had confuged them with the ducts. 
Czerny ('90) showed that twenty-four hours after the suspension of nursing some corpuseles of different diameters and some polymorphonuclear levoocytes appear in human milk.

Mori ('92) confirmed in all points the description of czerny and followed the resorption of the intraralveolar liquid. He found that the products elaborated are zesorbed little by little by the levcocjtes.

Duclert ('93) observed the form of the mammary epithelium of the gland of a cow whose udder had not been emptied for fortyeight hours and that of a guinea pig thirty hours after weaning. He saw distended alveoli filled with a thick granular coagulum which contains numerous droplets of fat. The epithelial cells are very flat and have a very reduced protoplasm; their borders neighboring the lumina of the alveoli are very irregular. These epithelial cells contain also some large fatty droplets refolding and deforming the nucle1. Duclert also noted that the glandular cavities diminish in volume in the mammary gland of a guinea pig fifteen hours after weaning. He further held that the cells detached from the membrana propria in the course of involution are resorbed.

Iimon ('02) states that in guinea pigs the cessation of lactation brings about profound modifications in the structure of the mammary gland, in both stroma and epithelium. He found that sections of the mammary gland taken eight days after weaning show the acinl lined with somewhat low epithelial cells, well defined on the side of the lumen but with 1ll-defined lateral borders. The center of the cell is occupied by a rounded or slightly ovold nucleus which in aspect differs greatly from the nuclei auring 
secretion. The nuclear membrane is less apparent. The chromatin substance is scattered through the whole nuclear area in the form of small granules. The nucleolus has completely disappeared. No trace of amitotic division or of nuclear degeneration was found. The oytoplasm is perfectly homogeneous in all 1 ts parts, no more enclosures (granules) in the alveolar region and no chromatic filaments in the basal region. At a more advanced stage of regression, twelve days after weaning, the secretory acini are crowded by the invasion of connective tissue stroma. The epithelium is flattened and poorly defined. It is reduced to a small protoplasmic band presenting here and there very small nuclei without specific characteristies. The alveoli, in the course of degeneration, disappear little by little, choked by connective tissue in greater abundance.

Berka ('1l) summarizes his conclusions concerning the phenomena in the human mammary gland as follows:

"Das Bild der Drilse vor und nach der Geburt ist gleich, und entspricht auch der stillenden Mamma. Verlinderungen (Involution) entstehen bei Nichtstillen.

Die Involution kennzeichnet sich zunllohst durch Sekretstauung (Erweiterung der Fndblaschen), Verbreiterung des Bindegewebes zwischen den Acinis, Verkleinerung der Lappchen, wobe1 die Bindegewebssepta mlichtiger werden.

Dabei erhyht sich wieder der zellreichtum des Bindegewebes, ohne jedoch die Intensitat desselben vor der Sohwangerschaft (Infiltrat) zu erreichen.

Schliesslich schwinden die Lïppchen ganz, oder es verbleiben Reste von ihnen (Gruppen von Fnablaschen; mangelhafte Involution). 
Die zelligen Infiltrate an solchen stellen konnen auch nach Schwund der İ̈ppohen persistieren.

Das Bindegewebe, welches jetzt zum Raumersatze neugebildet wird, flurt aft viele frische (neugebildete) elastische Fasern.

Das Protoplasma der Acinuszellon fthrt Fettropfen aft lange Zeit nach beendetem St1llgeschaft; im Iumen der Milchglinge findet sich dies oft zeitlebens."

Schil ('12) describes the phase of regression in the mammary gland of the rabbit as follows:

For a few days following the cessation of nursing the mammary gland still shows feeble secretion. This secretion accumalates in the alveoli and distends them, increasing the alveolar tension and depressing the epithelium. Sections of the mammary gland. shortly after the beginning of weaning in some respects resemble those at the end of pregnancy. The milk transforms itself little by little into colostrium.

With the decrease in volume of the glandular eavities, certain alveoli manifest signs of returning to rest: their epithelium is oubical, with a cellular membrane distinctly defined on the side of the lumen; the nucle1 are oval and ocoupy the center of the cell; the cytoplasm does not present any sign of secretory activity. The greater number of the alveoli show some symptoms of involution. The alveolar lumine are very reduced and the secretory ducts contain some 1solated and free cells. The cytoplasm of these cells is granular and each contains a nucleus which degenerates, resolving itself into fine granulations which are dispersed into the eytoplasm. It is a process of involutionary pyonosis. These cells are detached from the membrana propria 
and are destined to be destrojed, and resorbed, as stated by Duclert.

The connective tissue stroms distends, takes a fibrillar aspect, with large meshes. The connective tissue cells are abundant; one observes numerous lymphatic lacunae, some very fine. and nontilated capillaries. The connective tissue forms some large bands which enclose certain lobes and clasp the acini.

The process of involution takes place rapialy and some weeks after the end of nursing the gland has returned to the adult state. In animals with spontaneous ovrlation, the regression depends upon the frequency of ovulations; thus in woman, whose ovulation is spontaneous and of relatively short period, the regression is weak and the mammary glands after lactation return to the stage of the mammary gland at puberty; in other mammals with spontaneous ovalation, but in which ovulation occurs at long intervals, the regression can bring the mammary glands back almost to the infantile stage.

Wahl ('15), working upon the blood-vessels of the mammary gland in the rabbit, has also made some observations upon involution of the gland in this animal. He finds that: "Within two weeks after weaning the gland appears much thinner than during lactation, owing chiefly to the disappearance of milk from the ducts and to the retrograde metamorphosis which becomes well marked first in the alveoli and later in the ducts. The alveoll first shrink in size, then the alveolar cells degenerate and are absorbed, but usually a duct stem remains as a small group of epithelial cells with merely a small lumen or no lumen. The stroma appears relatively greatly increased as the alveoli 


\section{Page 9.}

disappear. Different parts of the same gland undergo quite unequal retrograde metamorphosis. The alveoli of one auct may disappear, while along another duct they may appear to be still in the secreting stage. Alveoli of this kind may persist for at least several month's after lactation. The walls of the main ducts and their branches first collapse as the contained milk secretion is absorbed and then gradually shrink in size.

As the alveoli are absorbed the surrounding capillaries disappear so that in the lobule the relatively thick walled venules and arterioles seem disproportionally large compared with the capillary field which they supply. The capillaries about the ducts likewise in part disappear. Thie various arteries and veins of the gland appear for a time tortuous and shrunken, but gradually they come to resemble more and more the vessels of the gland of the virgin adult. Several characteristic differences, however, remain. The ducts are much longer and more ramified than in the virgin animal and the number of veins and arteries supplying them is greater. The larger arteries are more regularly accompanied by veins and the large veins by arteries."

MoFarland ('21) in cases of 'abnormal involut1on' in the human mammary gland, describes a variety of appearances which he finds very puzzling. There is diffioulty in deciding what is to be regarded as normal in the eycle of changes including the involution of the gland. From a study of the variations in structure and appearance found in about 200 apparently normal mammary glands, he concluded that several normal structural types will have to be recognized. 
Myers and Myers ("2l), working with female albino rats and using cleared preparations, were able to demonstrate definite mecroscopic changes in the mammary gland auring the period of involution following the cessation of normal lactation. At the end of gix hours the masses of glandular tissue were found considerably enlarged. They explain this enlargement as probably due to the accumalation of $\mathrm{milk}$, and found that it continued through the forty-eight-hour stage. In the four-day stage the masses of glandular tissue had decreased considerably in size, while at the end of five days the glands are not more than onehalf the size of those taken at fortyright hours. In the stages taken at the end of two and three weeks the glands very closely simulated those of adult virgin animals. 


\section{Material and Methods.}

The material for this investigation consists in a series of 27 primiparous albino rats (Mus norvegicus albinus) from the colony in the Institute of Anatomy. The stages were selected as presented in the following tables ( 1 and 2 ). In the first colum the number for each rat is given. The letter indicates the series, the number preceding the decimal point is for the litter, and the number following designates the individual rat.

\section{Table 1.}

Serieg of Animals during Lactation.

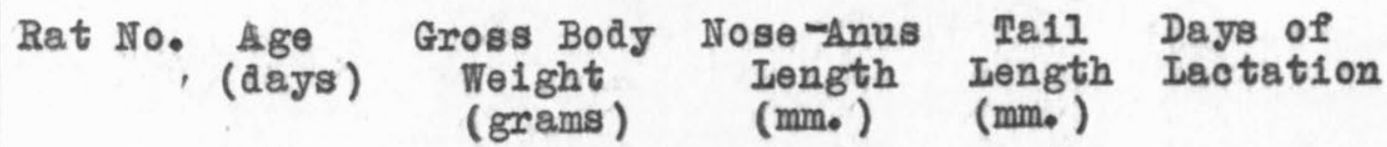

M $1.1 \quad 112$

125.0

160

143

0*

M $2.1 \quad 174$

153.4

172

150

3.5

M $3.1 \quad 210$

153.0

175

160

6.0

M $4.1 \quad 114$

112.0

153

150

7.0

M. $5.1 \quad 153$

133.0

170

158

9.0

M. 6.1

(?)

181.0

191

140

10.0

M $7.1 \quad 133$

131.5

160

155

14.5

M 3.2163

140.0

165

150

15.0

M $3.3 \quad 144$

106.5

162

150

17.0

II $7.2 \quad 126$

142.0

173

153

21.0

M $3.4 \quad 148$

107.5

167

150

21.0

*Had just given birth to a litter, which had not nursed. 


\section{Table 2.}

Series of Animals during Involution.

Rat No. Age Gross Body Nose-Anus Ta11 Time $\begin{array}{llll}\text { Weight } & \text { Iength } & \text { Iength } & \text { since } \\ \text { (grams) } & (\mathrm{mm} \cdot) & (\mathrm{mm} \cdot) & \text { Nursing }\end{array}$

\begin{tabular}{|c|c|c|c|c|c|c|}
\hline M 8.1 & (?) & 253.0 & 199 & 193 & 24 & hours \\
\hline M $\quad 9.1$ & (?) & 174.5 & 181 & $-\infty$ & 44 & " \\
\hline M 10.1 & 176 & 157.5 & 184 & 153 & 47 & " \\
\hline M 11.1 & (?) & 264.5 & 207 & 185 & 3 & days \\
\hline M 12.1 & 248 & 186.2 & 190 & 151 & 3 & " \\
\hline 110.2 & 183 & 150.5 & 182 & 160 & 4 & n \\
\hline I 13.1 & (?) & 224.5 & 197 & 152 & 5 & " \\
\hline 10.3 & 190 & 189.9 & 190 & 173 & 6 & " \\
\hline & & , & & & 0 & \\
\hline 14.1 & 170 & 165.7 & 177 & 154 & 8 & " \\
\hline 15.1 & (?) & 190.5 & 188 & - & 9 & " \\
\hline M 16.1 & 173 & 229.4 & 200 & 169 & 13 & " \\
\hline 417.1 & (?) & 255.1 & 212 & 177 & 16 & n \\
\hline M 18.1 & 208 & 154.0 & 182 & 156 & 22 & " \\
\hline 10 & & & & & & \\
\hline 19.1 & 189 & 149.8 & 77 & 143 & 28 & " \\
\hline 20.1 & 213 & 145.8 & 179 & 152 & 3 & months \\
\hline 21.1 & 281 & 153.2 & 179 & 148 & 3 & $n$ \\
\hline
\end{tabular}

Table 3.

Series of Virgin Animals.

$\begin{array}{ccccc}\text { Rat No. } & \begin{array}{c}\text { Age } \\ \text { (days) }\end{array} & \begin{array}{c}\text { Gross Body } \\ \text { Weight } \\ \text { (grams) }\end{array} & \begin{array}{c}\text { Nose-anus } \\ \text { Length } \\ (\text { mm. })\end{array} & \begin{array}{r}\text { Tail } \\ \text { Length } \\ \text { (mm.) }\end{array} \\ \text { M 16.2 } & 179 & 150.9 & 183 & 151 \\ \text { M 26.1 } & 135 & 196.1 & 189 & 159 \\ \text { M } 27.1 & 123 & 139.6 & 173 & 138\end{array}$


Page 13.

The animals were killed by ether and immediately weighed and measured, the data being given in tables 1 and 2. A longltudinal incision in the dorsal mialine from the tip of the nose to the root of the tail was then made quickly with a scissors. Working laterally from this incision on either side, the integument with the mammary glands attached was carefully removed, by dissecting with a sharp safety razor blade along the fascial plane between the glands and the underlying muscle. In this way the whole skin with the mammary glands still intact in their normal position was secured.

The stages in lactation were used for cleared as well as for histological preparations. A modification of the method employed by Myers ("16) was found to be more suitable for the gland at this stage. The whole integument after removal was placed flat upon a cork sheet with the glandular surface up and held in as nearly normal a position as possible by small wooden pegs. The whole preparation was then fixed in Zenker"s solution for 24 hours, washed for 24 hours in running water and then carried up through the various grades of aloohol to 80 per cent. Appropriate pieces for histological sections were removed from selected areas. At this point the specimen for the final cleared preparation was secured. Starting at one edge, the tela subcutanes was split from the corium and this process continued over the entire area of the integument, using a sharp safety razor blade to accomplish the separation. Thus a very thin fascial envelope containing the glandular tissue was obtained. This envelope was then dehydrated, carried through xylol into beechwood ereosote, mounted upon a glass frame, placed in a thin specimen jar of appropriate size and 
covered with beechwood creosote. Staining was found to be unnecessary, for after several weeks in beechwood creosote the darker glandular tissue could be seen in bold relief against the relatively transparent fascial envelope.

Only histological preparations were made from the stages of involution. The skin with the glands was removed (as above), laid flat upon the table, and the inguinal and abdominal glands removed in toto from each side by lifting gently upon the gland with fine forceps and outting with sharp pointed scissors the tela subcutaner between the gland and the corium. Tangential and transverse sections were then out from these glands and placed in flxing fluids.

As fixatives, Zenker's solution, 10 per cent formalin, and Flemming's strong osmic thromic acid solution were used. Parafin sections were cut at 5 micra. Sections of zenker's fixation were stained with hematoxylin and eosin, cresyl violet, Mallory's connective tissue stain, Unna's orcein, and Heidenhain's iron-alum hematoxylin, with and without counterstain of acid fuchsin. Sections of Flemming's fication were mounted both without stain and with Heidenhain's Iron alum hematoxylin stain. Sections of formalin fixation were cut as frozen sections and stained $\mathbf{x}$ both with hematoxylin and eosin and with Sudan III for fat (by courtesy of the Department of Pathology). Bell's ('14) method, a combination of the techniques of Dietrich and ciaccio, for differentiating between neutral fats and lipoids was tried, but was found to be unsatisfactory for mammary gland fat. 


\section{Observations. \\ A. Gross Changes.}

The nipple during lactation is long and prominent and can easily be drawn out to double its usual length. The hairs about the base of the nipple for a distance of about $2 \mathrm{~mm}$. have been worn away and thus appears what might be termed the areola of the nipple. After weaning, the nipples become progressively smaller in size and less prominent; and by the end of two weeks they reach a size about double that of the virginal nipple. The hairs have again begun to grow in about the base of the nipple. The nipple probably does not undergo any appreciable decrease in size after this time, for in most non virginal rats the nipple is apparently about twice the size of that of a virgin.

In the recently killed animal during lactation, the mammary glands are seen as well tefined masses, elevated above the surface of the rest of the skin. In the stages of involution, after two weeks, the glands are much smaller and less clearly outlined.

Cleared preparations of the glands in lactation showed quite conclusively that the macroscopic aspect of the gland remeins unchanged throughout lactation and is the same as at the end of pregnancy. The glandular tissue appears as two dark $V$-shaped masses in the thoracic and inguinal regions. The apex of the first $\nabla$ lies slightly cephalad to, or at the level of, the fore limbs and is formed by the median overlapping of the glandular tissue of the first pair of thoracic glands. From this apex, the mammary masses extend latero raudad, being formed on each side by the overlapping of the first, second and third thoracic glands, and lying along the medial aspect of the forelimbs. The caudal ends of these masses do not quite reach those of the second $\nabla$. The apex of the second $V$ 
lies slightly cephalad to the urethral orifice and is formed by the median overlapping of the second pair of inguinal glands. From this apex, the mammary masses extend latero rephalad, being formed on each side by the abdominal, and first and second inguinal glands, and lying along the medial aspect of the hind limbs. Owing to the great engorgement of the glands with secretion and the overlapping of the glandular tissue, the individual ducts and lobules could not be made out (in gross preparations) except at the periphery.

\section{B. Histology auring Lactation.}

In general, any stage of the series of glands in lactation may be taken to represent the characteristic appearance of the gland during this period and at the end of pregnaney. Vabiations oocur, however, both in different individuals and in diferent parts of the gland. The appearances also vary somewhat according to the technique used.

A frozen section of a gland at ten days' lactation, with hematoxylin-øosin stain (Fig. 2), shows the general structure very well. This type of preparation shows most satisfactorily the relative proportion between parenchyma and stroma, the relative size and condition of the different lobules, and the position and relations of the ducts and the blood-ressels.

Parafin sections stained with hematoxylin and eosin present much the same pioture as the frozen sections. Being thinner, they make possible the study of histologieal details under grester magnification, but do not bring out quite so well the grosser architecture of the gland. 
Frozen sections of the ten day stage, stained with sudan III (Fig. 6), present the same general picture as similar sections stained with hematoxylin and eosin. In addition they bring out more clearly the fat cells in the strome and also show the presence of fat droplets in the lumins of the acini and the ducts and in the epithelium of both ducts and aolni.

Flemming's osmic mixture was also used, followed by paraffin sections at various stages in lactation. They show less clearly the general structure of the gland, since only the periphery is well penetrated by the osmic acid. The fat is well stained by this fixation. In the lumina and epithelium it usually appears in small spherical aroplets. Here and there the lumen of an acinus remains filled with an almost completely black mass formed by the fusion of fat droplets. The fat cells of the stroma, however, appear as larger and more irregularly shaped structures.

Heldenhain's iron hematoxylin stains of parafin sections show the nuclear structure most clearly.

The cresyl violet staining of paraffin sections is of considerable value. This gives a very clear picture, sharply marking off the parenchyma from the stroma. It differentiates the mast cells, and brings out clearly the cytological details. The connective tissue and the alveolar contents, however, do not take the stain well.

Mallory's connective tissue stain with parafein sections brings out aistinctly the grouping of the glandular epithelium into lobules and reveals the septa of collaginous fibrous connective tissue between them. 
Unna's orcein stain demonstrates the presence of elastic tissue fibers in the septa. The ducts are sharply marked out in these sections by the very definite surrounding sheath of elastic tissue fibers. The acini are also demarcated by the very fine septa and fibrillae prolonged out into the interacinous spaces.

The general arrangement and proportions of parenchyma to stroma (Figs. 2 and $\eta$ ) are seen to be practically the same in all sections at any stage of lactation and at the ond of pregnancy. The glandular parenchyma is in great preponderance, being distributed in the form of definite, closely packed lobules which reduce the stroma between them to relatively thin septa. Ths distention of the ducts and acini with secretion is fairly uniform. Dilated blood vessels are quite numerous in the connective tissue septa, while between many of the acinl are seen small, widely dilated eapillaries.

The lobules all present about the same general appearance, except for a narrow zone of glandular tissue about the periphery of the section. This zone presents smaller lobules with less widely distended acini which are composed of taller oells, take a deeper bluish stain and contain little or no secretion. This zone is present in whole or in part in all sections, although in a few sections it is only suggested by a few such lobules at the periphery of the sections More frequently it is found partially or wholly surrounding a cross-section passing through the gland.

A small lymphnode is frequently noted in sections of the series (from the abdominal region). It appears as a small, well circumseribed mass of lymphoid tissue, well embedded in the gland and surrounded by a thin, compact connective tissue capsule. 
A study of the various sections under high power reveals many details of structure. The ducts are recognized by the more dense connective tissue sheath which surrounds them and in many instances by the direct communication between them and adjacent lobules (Fig. 2). They are also usually distinguishable from the neighboring acini by the fact that if their epithelium is of the same height as that of the aini their lumina are mach larger, while if their lumina are of the same size as those of the acini their epithelium is usually taller. A careful study of all sections shows that the epithelium during lactation is of a single layer, regardless of the size or degree of distention of the duct. Cell-boundaries are not demonstrable in the distended ducts and appear only indistinetly in the dusts with columnar epithelium. The eytoplasm shows no details of importance. The nuoleusplasma rat10 would apparently be relatively high. The nuclel appear relatively large and vesicular, with definite outlines. The chromatin is mostly massed in one or two small clumps near the center, giving the appearance of nucleoli, or clinging in smaller masses to the nuclear membrane. In a smaller number of nuclei the chromatin is distributed more diffusely, giving the whole nucleus a ark appearance. Occasionally a small, round, rather dense nuclous, suggesting a lymphocyte, is found (F1g. 7). Mitosis was observed in only one cell of the epithelium lining the ducts. The lumina appear more or less distended with milk, showing a homogeneous eosinophile substance (protein?) in which are numerous spherical droplets of fat (as demonstrated by osmic acid and sudan III). While fat droplets and granules are found in the lining epithelial cells, in general the duots seem to show less secretory activity than do the acini. 
The acini usually appear round and well distended, although there are variations in form (Fig. 7 ). As compared with that of the duots, the epithelium of the acini is flatter, more granular and more vacuolated. It presents a quite uneven border on the side of the lumen, due to the greater number of fat droplets in the various stages of secretion and discharge. Nothing suggesting the so-called decapitation" (detrohment of the apex of the cell and Its discharge into the lumen), was observed. The average number of cells in the circumference of an acinus is diffioult to determine but the number of nuclei seen in a section apparently averages between fifteen and twenty.

The acini in portions of the gland exhlbiting the greatest amount of secretory activity are characterized by: (1) the large vesioular nuelei with the chromatin distributed in small clump; (2) uneven, indistinct cell-boundaries on the side of the lumen; (3) highly granular and vacuolated eytoplasm; and (4) distention of the acini with secretion containing numerous droplets of fat. Mast cells are relatively numerous (Fig. $\eta$ ) and appear to be distributed quite evenly throughout the connective tissue stroma, as demonstrated by the cresyl violet stain. They are relatively large in size with deeply stained nuclei and coarse, purplish, granular eytoplasm.

Nothing suggesting a membrana propria was observed in the sections with the various methods of preparation. 


\section{Histology during Involution.}

The various stages up to three months after weaning will be successively considered.

Twenty-four to forty-elght hours after weaning. - - Stained sections of the gland present practically the same appearance as during lactation. The parenchyma and stroma bear the same relative proportion to each other. The acini are widely distended with secretion and the epithelium still shows apparent secretory activity. In general, the ducts appear somewhat more widely distended with homogeneous contents than during the period of lactation. The characteristic peripheral zone of the gland is still present during this time.

Three-day stage (Figs. 3 and 8). -The perenchyma now appears somewhat reduced in proportion to stroma, in comparison with the preceding stage. This is shown by comparison in all sections of these stages, especially the frozen sections. The glandular substance appears more definitely grouped into small masses or lobules (Fig. 3). The number of distended alveoll is markediy decreased with a progressive increase in the number of collapsed alveol1. Secretory activity, however, appearsaquite well marked in many alveoli throughout the section. But in other alveoli definite signs of cessation of secretory activity and beginning atrophy are already evident. Such an area presents a character1stic appearance (Fig. 8). The alveoli are smaller and contain little or no secretion. Large droplets of fat are frequently seen in the acinar cells, reaching to the very lase of the epithelial cells, and in some cases crowding and deforming the nuclei. The cytoplasm appears more granular and stains less deeply. Many of 
the nuclei are somewhat irregular in outline and are hyperchromatic, taking a deeper stain. A few nuclei have become pyonotic. Four-day stage. --Stroma and parenchyma in sections now appear about equal in amount. The ducts as a rule are still well distended. They now appear more prominent in the section, owing to the absolute decrease in the number of alveoli. The relative number of distended alveoli seems greater than in the three-day stage (perhaps an individual variation). Secretory activity is still evident in some places; but beginning atrophy, as deseribed in the preceding stage, is almost universal. The nucle1 in general have lost their vesicular appearance and now appear more irregular in outline and stain deeply (hyperchromatic). Pyenosis is more frequent.

Five-day stage (FIge, 4 and=0), - Frozen sections of this stage show still more marked decrease in amount of glandular tissue, the glandular groups containing only a small number of alveoli and appearing as small islets in the fatty connective tissue stroms. The glandular tissue is replaced by an increased amount of adipose tissue. The lumina of the acini and ducts are quite small and oontain spherules of fat. Small fat aroplets are still seen in the eplthelium of most acini.

Six-day stage. - In this case the parenchyma greatly exceeds the stroms in amount, the condition closely resembling that found in the forty-four hour stage. The secretory activity is very marked in the lactiferous epithelium. This apporently represents a marked individual variation, where for some reason the involution of the mammary gland has been delayed. The possible relation of such variations to the estrus oycle is mentioned later. 
Fight-day stage (F1gs. 5 and 9), - Here once more the stroma exceeds the parenchyma in amount. The glandular tissue is reduced to small cords with small lumina or no lumina at all. The glandular tissue, however, in most regions is still greater in amount than in the above-described five-day stage (probably an individual varlation). Frozen sections stained with Sudan III show that the small lumina of the duets contain fat droplets and that ting fat droplets are also present in the epithelium. True secretory activity is apparently absent (Fig. 10). The cell-cords are evidently undergoing atrophy. The cell structure is indistinet; the oytoplasm seems to be reduced to a small amount of granular debris. The great majority of the nuclei are small, dark-staining and irregular. Many nuclei appear pyenotic and some are broken up. The nuclear material is evidently being removed both by karyorrhexis and karyolysis. The nuclear substance greatly exceeds the eytoplasm in amount. Cresyl violet stains show these conditions very elearly.

Nine-day stage. - The gland has now reached a more advanced stage of involution, so that the structure here begins more nearly to resemble that of the resting adult virgin gland. A very few persistent acini are still present with atrophic epithelium, and a few of the smaller ducts still contain secretion within the lumen. Thirteen, sixteen, twenty two and twenty - 1 ight day stages. -The structure here elosely resembles that of the virginal resting gland. Only a few ducts are seen passing through the stroma. These ducts now seem to possess a double layer of epithelium (which did not appear during lactation), with an inner layer of columar and an outer layer of low epithelial cells. The eytoplasm 


\section{Page 24.}

is relatively more abundant; the nuclei are apparently smaller and less vesicular than in the lactating stage. They take a deeper stain and their chromatin is more evenly distributed. Bach duct is surrounded by a connective tissue sheath. No membrana propria is observed. The stroma is composed ohiefly of adipose tissue through which the ducts pass. In some sections the adipose tissue seems to be arranged in lobules separated by fibrous connective tissue septa.

Three months' stage. --Sections of these stages present apparently the same structure as that of virginal resting glands. Apparently no further demonstrable changes have taken place at the end of three months, beyond those observed in the stage at thirteen days. Some eross-gections of the gland showed no glandular tissue whatever (probably depending upon the place from which section was taken); other sections exhibited the same amount of glandular tissue as earlier stages (thirteen days and later). Blood 7 sessels are apparently somewhat more numerous and run a more tortuous course than in the virginal gland. 


\section{v. Discussion. \\ A. Lactation.}

The significance of the so-called 'peripheral zone' of the mammary gland is difficult to determine. Its constant occurrence, either wholly or partly surrounding the section, would clearly indicate that it is not merely accidental. That it is an artefact and due to the manner of preparation appears improbable. Fixation or staining methods could hardly account for the small size of the lobules, the greater height of the epithelium, and the lack of contents in the lumina. The technique of embedding and sectioning likewise fails to account for 1t, since it appears not only in parafin sections but also in frozen sections of formalin material which are handled quite differently. Mechanical manipulation or pressure during preparation would scarcely produce a uniform diminution in the size of the alveoli. Such manipulation rather causes a general flattening of the alveoli, as shown in oertain parts of a few sections which were accidentally subjected to local pressure with the forceps during removal of the gland. It would therefore appear that this peripheral zone has a definite morphological significance. Possibly it may represent a layer of incompletely developed, reserve alveoli, which have not been called into function by the demand upon the gland. Or it may represent a zone in whioh for some reason the nutritive conditions are less favorable than elsewhere. It may be recalled that other parenchymatous glands frequently present a peripheral zone of atrophic appearance.

The small lymph node in the inguinal region was noted by Myers ('16) in the mammary gland of the albino rat. O'Donoghue ('12) found an analagous gland beneath the mamary gland of Dasyurus and notes that its size varied somewhat with the activity 
of the gland. This gland could not be observed in my cleared preparations due to the opacity of the glandular tissue. Iymphnodes associated with the mammary gland appear very distinctly in Myers' gross cleared preparations. In all cases a chain of two or three small nodes is found in the region of the abdominal gland. Since I always took the piece of gland for histological preparation from the region of the abdominal and first inguinal glends, the frequent occurrence of this node in stained sections is easily understood.

The epithelium in all ducts of my stages in lactation appears to be composed of a single layer of cells. Roberts ('21) shows in his figures a duct from a gland of a rat nineteen days pregnant, with two layers of epithelium. This would indicate that the transition from two layers to one layer takes place during the last days of pregnanoy. As above noted, the two layers apparently reappear in the ducts toward the close of the period of involution.

A count of the nuclei in several acini indicates that the average number of cells in a section of each acinus lies between fifteen and twenty. Roberts ('21) found that the average number of cells about the lumen of the acini is eight, ranging from six to ten. This would indicate that the number of cells per acinus has increased in the latter part of pregnancy. But this is very doubtful, since cell-division is rarely found at this time. It may be a matter of chance variation.

My results in general agree will with the now generally accepted view of the production of milk by a purely secretory activity of the glandular epithelium.

Colostrum corpuscles were not observed in any of my sections 
of the end of pregnancy stage or in any of the stages of lactation. Only one cell resembling colostrum was found and that occurred in the stage three days after weaning (Fig. 8). However, no special study of colostrum was made by me. There apparently is no evidence to show that the transition from colostrum to pure milk secretion takes place after parturition in the rat. Roberts ('2l) has described colostrum formation toward the latter end of pregnanoy in the rat. Schil ('I2) mentions a transitory or intermediate phase, lasting for five or six days after parturition in women, during which the colostrum becomes transformed and makes place for the normal milk secretion.

The mast cells are probably of no significance as regards lactation. Roberts ('21) found them in great numbers in the gland during pregnancy. They are also present in the virgin gland. It would therefore seem that they are present in the gland during the whole cyele.

\section{B. Involution.}

The relation of parenohyma to stroma remains nearly the same as during lactation for the first two days after weaning. After two days the parenchyms decreases in relative amount. It usually shows well marked involution by the fifth day, and by the ninth day begins to approach its virginal resting condition. Variations, however, do occur as evidenced by the fact that the glandular tissue in the eight day stage was relatively greater in amount than in the five-day stage. Similarly the six-day stage appeared scarcely different from the twenty-four hour stage. These cases serve to 1llustrate the marked individual variability in the rapidity of involution in the mammary gland. Variability in 


\section{Page 28.}

different parts of the same gland was also noted. This variability of different parts of the same gland was noted in the rabbit by Sohil ('I2) who states that during the stages of lactation and involution the different lobules present variable aspects and that different acini are not in the same stage of secretion. Variability in different individuals and in different parts of the gland in the same individual is also characteristic of the human species (MoFarland '21).

Even in the resting mammary gland there may be considerable difference in the amount of parenchyma, as shown by Bouin and Ancel ('09) and Frank and Unger ('Il) in the rabbit, and by Sutter ('2I) in the rat. These variations are ascribed chiefly to varying effects of the corpora luter in different parts of the estrus cycle. It is quite possible that similar effects may likewise be responsible for some of the individual variations found in the mammary gland during the period of involution. The secretory activity of the gland does not seem to be decreased before forty-eight hours after weaning. In the threeday stage secretory activity appears still quite marked in many alveoli, but in some alveoli secretory activity has evidently come to a standstill with the beginning of atrophy. The amount of secretory activity shows in general a progressive decrease in the four and five-day stages. The six-day stage represents a marked variation, resembling very closely the forty-eight hour stage. The eight-day stage shows no secretory activity. This would indicate that secretory activity becomes greatly reduced after forty-eight hours and that by eight days it is usually absent altogether. 
The lumina of the acinl do not show any appreciable increased distention during the forty-eight hours after weaning. This is rather difficult to explain in view of the apparent oontinued secretory activity during this time. Possibly the products of secretion are absorbed as fast as they are produced. Moreover, in view of the fact that no actual measurements were taken and comparisons were made merely by inspection, it is quite possible that a slight increase in the diameter of the alveoli might not be perceptible. The findings of other investigators would make this seem quite probable. Schil ('12) states that for a few days after weaning in the rabbit the mammary gland still shows feeble secretion, the products accumulating in the alveoli, and distending them. Berka ('11) also noted increased distention in the alveoli of the human mammary gland after weaning. Myers and Myers ('21) have also demonstrated an actual increase in size of the glands in gross cleared preparations after six hours and up to forty-eight hours.

The first signs of involution are found in the threeday stage and become progressively more marked with each successive stage (excepting individual variations) until about the thirteenth day, when the gland again resembles the virgin resting gland very closely. Berka ('Il) would consider the increased distention of alveoli immediately after weaning an early step in involution. It would probably be better to consider this phenomenon as a result of continued secretory activity of the gland, for it probably occurs many times during the course of normal lactation, especially if the gland is not nursed frequently, without being followed by actual involution. Involution is apparently first evidenced by the occurrence, in the acinar epithelium, of larger fat droplets 
which crowd the nuclei and deform them; also by a decrease in the size of the alveoli and a loss of the contents in their lumina. Duclert also noted large fat droplets in the epithelium of glands in involution. There is no indication of the persistence of collapsed glandular acini (Billroth's view).

Nuclear changes seem to be very characteristic of the various stages of involution. They have also been described by Limon as undergoing changes with involution, especially as regards change in shape with a more diffuse distribution of the chromatin. Schil also describes nuclear degeneration (pyonosis and karjorrhexis). Duclert and Schil have mentioned the detachment of cells from the membrana propria and subsequent absorption.

Wall ('15) found that during involution the alveoll first shrink in size, then the alveolar cells degenerate and are absorbed, merely the ducts remaining as small groups of epithelial cells, with a small lumen or no lumen. Study of my sections has led to the conolusion that the disappearance of the acini is accomplished first by a simple atrophy of the cells, with shrinkage in the size of the cells and the alveoli. With progressive atrophy of the eytoplasm, the nuclei become pyonotic and finally the whole cell disintegrates and disappears.

Apparently during involution the contents of the lumins and duets are removed by simple absorption, as found by Wahl in the rabbit. There is nothing to indicate that in the rat leucocytes have anything to do with the removal of the secretion, as found by Czerny and Mori in the human gland. Schil states that th rabbits the secreted milk transforms itself little by little into colostrum. No indication of such a process is found in the rat. 
Great variability in the involution in the mammary gland has been observed by various investigators. Berka states that in the human mammary gland remains of lobules, groups of alveol1, may remain as evidence of faulty involution and that epithelial cells may long persist and contain fat after shrinkage of the lobules. Wahl in the rabbit found that different parts of the same gland undergo quite unequal retrograde metamorphosis, and that alveol1 in various stages of involution may persist for at least several months after lactation. These findings are in general agreement with my results; but the possibility of changes due to the estrus cycle (corpora lutea) mast always be kept in mind. Wahl found that during involution in the rabbit the various arteries and veins of the gland appear for a short time tortuous and shrunken. He states that several characteristic differences between the virginal and involuted gland remain, the ducts remaining much longer and more ramified than in the virginal animal and that the number of veins and arteries supplying them is greater. This is in agreement with my eindings in the rat, in which I find also the nipple malntaining a part of the hypertrophy whioh it undergoes during lactation. 


\section{Page 32.}

VI. Summary.

1. The macroscopic and microscopic structure of the mammary gland remain practically unchanged throughout the period of lactation in the albino rat.

2. The epithelium of the ducts of the mammary gland throughout lactation is single-layered.

3. The mammary gland possesses a fairly constant peripheral zone of characteristic structure throughout lactation and early involution. This is a somewhat atrophic or undeveloped zone of uncertain significanee.

4. The mammary gland shows very little change during forty-right hours after weaning. The alveoli probably tend to become somewhat more distended by the accumulation of secreted milk.

5. Secretory activity does not seem to be diminished before the third day after weaning. The cessation of secretion varies in different individuals and in different parts of the glend. Fight days after weaning no secretory activity is apparent.

6. A progressive increase in stroma and decrease in parenohyma takes place after the second day, the gland usually approaching the condition of the normal resting gland by the ninth day.

7. The removal of the epithelium of the acinus is accomplished by collapse of the acinus, and simple atrophy of the epithelium, followed by pycnosis and karyorrhexis or karyolysis. Large fat droplets frequently occur in the epithelial cells of the acini from the third to the fifth day of involution. 
8. At the terminal stage of involution the structure of the mammary gland is very similar to that of the resting gland in the adult virgin.

9. The mammary gland is subject to considerable variability in rate and character of involution, either in different individuals or in different parts of the same gland. The former may be due in part to variation associated with the estrus cycle. 


\section{Bibliography.}

Ancel, P., et Bouin, P. 1909 Sur la fonction du corps jaune. Action du corps jaune vral sur la glande mammaire (troisiome note pr(liminaire). Compt. rend. Soc. Biol., T. 66, p. 605. Bell, B. T. 1914 On the differential staining of fats. Jour. of Path. and Bact., Vol. 19, pp. 105-113.

Berka, F. 1911 Die Brustarlise verschiedener Altersstufen und whrend der Schwangerschaft. Frankfurter Zeitschrift fltr Pathologie. Bd. 8, 203-256. Billroth, Th. 1887 Diseases of the female mammary glands. Cyclopaedia of Obstetrics and Gynecology. Vol. IX, p. 1-158. Wm. Wood and Co., New York.

Czerny, A. 1890 Ueber die Brustdrltsensekretion beim Neugeborenen und Uber das Verhgltnis der sogenannten Kolostrupkorperchen zur Milchsecretion. Sep. Abdr. aus d. "Festschr. zu

E. Hennoch's 70. Geburtstag." 34 p. (Cited by Schil.) Duclert, I. 1893 ítude histologique de la sécrétion lactée. Thèse de Kontpellier. 79 p. (Cited by Schil.) Frank, R. T., and Unger, A. 1911 An experimental study of the cause which produce the growth of the mammary gland. Archives of internal medicine, Vol. 7 .

Limon, 1. 1902 Phénomènes histologiques de la sécrétion lactée. Journal de l'anatomie et de la physiologie, T. 38, pp. $14-34$. MoParland, Joseph 1921 Preliminary remarks upon the functional varlations of the normal human mammary gland. Proc. Amer. Assoe. Anat., Anat. Rec., Vol. 21, No, 1, pp. $72 \rightarrow 3$. Mor1, A. 1892 Sulle variazioni di struttura della ghiandola mammaria durante la sua attivita. Sperimentale. Mem. orig., F1renze, vol. $46, \mathrm{pp} .444-456$. 
Page 35:

Myers, Frank J. and Myers, J. A. 1921 Studies on the mammary gIand. VIII. Gross changes in the mammary gland in the female albino rat during the period of involution. Proceedings Amer. Assoc. Anat., Anat, Rec., V01. 21, No. 1, p. 74 .

Myers, J. A. 1916 Studies on the mammary gland. I. The growth and distribution of the milk-ducts and the development of the nipple in the albino rat from birth to ten weeks of age. Am. Jour. of Anat., Vol. 19, No. 3, pp. 353-389.

1917 Studies on the mammary gland. II. The fetal development of the mammary gland in the female albino rat. Am. Jour. of Anat., Vol. 22, No. 2, pp. 195-223.

1919 Studies on the memmary gland. IV. The histology of the mammary gland in male and female albino rats from birth to ten weeks of age. Am. Jour. of Anat,, Vol. 25, No, 4, pp. $395-435$.

1919a Studies on the mammary gland. VI. The development of the mammary gland from 1ts earliest appearance unt1l the period of pregnancy. Am. Jour. of Disesses of Children. V01. 18 , pp. 4-15.

O'Donoghue, C. H. 1912 Growth changes in the mammary apparatus of Dasyurus, Quar. Jour. of Micr. Science, Vol. 57, pp. $187-234$.

Roberts, F. I. 1921/ Changes in the mammary gland of the albino rat during the second half of pregmanoy. The Graduate School of the University of Minnesota, Papers from the Mayo Foundation for Medical Education and Research and the Medical school. Vol. I. (In press.) 
Page 36.

Schil, I. 1912 Recherche sur la glade mammaire, sur les phases qu'elle présente au ours de son évolution et lear determinisme. Those, Lyon.

Sitter, Monroe 1921 Cyclic changes in the mammary gland of the rat associated with the oestrus cycle. Proc. Amer. Asst. of Anatomists. Anat. Rec., Vol. 27, p. 59.

Wall, H. M. 1915 Development of the blood vessels of the mammary gland in the rabbit. Am. Jour. of Anat., Vol. 18, pp. $515-524$.

$10-205 \mathrm{M}$ 


\section{Explanation of Figures.}

Figures 1 to 5 inclusive are microphotographs of frozen sections fixed in formalin and stained with hematoxylin and eosin. The unit of magnification for these first five figures is 74 diameters. Figures 6 to 10 inclusive are drawings made with the aid of the camera lucida. Figure 6 is a drawing of a frozen section stained with Sudan III. The remaining material was fixed in Zenker's solution, embedded in parafin and stained with oresyl violet. All the figures are produced from transverse sections of portions of the gland from the abdominal-inguinal region.

Figures 1 to 5 show the general appearance of the gland in full lactation and up to eight days after weaning as compared to the resting virginal gland.

Figure 6 gives the disposition of fat in the stroma, epi thelium and lumina.

Figures 7 to 10 show the finer details of structure of the gland during lactation and involution.

1. Transverse section of the mammary gland of an adult Virginal rat (M 27.1). Section about $25 \mu$ thick; frozen section stained with hematoxylin and eosin. $x$ 74. The parenchyma consists only of a few ducts, Du, ramifying through the fatty connective tissue stroma, S. Fig. 10 of the gland twenty-right days after weaning gives a high-power view of a similar duct.

2. Transverse section of the mammary gland of a rat (M 6.1) in the tenth day of lactation. Section about $25 \mu$ thick; frozen section stained with hematoxylin and eosin. X 74. The parenohyma consists of definite, large lobules, I, with widely distended acini; the stroma has been reduced to thin connective tissue septa, s. 
Fig. 6 is a fat stain of another section of the same gland. Fig. 7 gives a view of the more detailed structure in a similar stage.

3. Transverse section of the mammary gland of a rat (M 12.1) three days after weaning. Section about $25 \mathrm{p}^{\mathrm{r}}$ thick; frozen section stained with hematoxylin and eosin. X 74. The. lobules, I, are smaller and the amount of fatty stroma, $F$, has increased proportionally. Fig. 8 shows the same stgge under high magnification.

4. Transverse section of the mammery gland of a rat (M 13.1) five days after weaning. Section about $25 \mu$ thick; frozen section stained with hematoxylin and eosin. X 74. The parenchyma is still further reduced in amount, the lobules, I, belng smaller than in the three day stage and the amount of fatty stroma, Fs, st11l further increased in amount.

5. Transverse section of the memmary gland of a rat (M 14.1) eight days after weaning. Section about $25 \mu$ thick; frozen section stained with hematoxylin and eosin. $\mathrm{X}$ 74. The parenchyma has again reached the stage similar to that of the resting gland, being composed chiefly of ducts. Parts of this section, however, show definite lobules resembling the lobules of the 5 day stage in size (variability). Fig. 9 is a high power view of a section of the same gland.

6. Portion of transverse section of the mammary gland of a rat (M 6.1) in the tenth day of lactation. Section about $25 \mu$ thick; frozen section stained with Sudan III. X 96. The fat is deposited as fet cells, F.C., in the stroma S, and as droplets, D, in the epithelium and lumina. Fig. 2 is a section of this same 
gland stained with hematoxylin and eosin. Fig. 7 is a drawing of a similar stage under high power.

7. Portion of transverse section of the mammary gland of a rat (M 3.2) in the fifteeth day of lactation. Section $5 \mu$ thiok; parafin seotion stained with cresyl violet. X 900. The acini are widely distended with secretion, Se, in which are suspended fat droplets, D, of various sizes. The eytoplasm, C, of the cells contains deeply staining granules and secretory granules. The nuclei are spherical and contain clumps of chromatin. The connective tissue stroma, $S$, is reduced to fine septa. Several mast cells, M, are shown. Figs. 2 and 6 are of the same stage but from a different rat (M 6.1).

8. Portion of transverse section of the mammary gland of a rat (M 11.1) three days after weaning. Parafin section $5 \mu$ thick, stained with oresyl violet. X 900. Definite signs of atrophy are evidenced by the presence of larger fat droplets, pd, and irregular and pyenotio nuclei, Py. A colostrum corpusole, Co, is shown in one of the alveoli. The eytoplasm is more irregularly vacuolated and stains less deeply. Fig. 3 is a low power view of a similar stage.

9. Portion of transverse section of the mammary gland of a rat (M 14.1) eight days after weaning. Parafin section $5 \mu$ thiok, stained with cresyl violet. X 900. Remains of collapsed alveol1, C.A., filled with degenerated, vacuolated oytoplasm. Pycnotic nucle1, Py, are quite numerous. The fat eells, P.C., have replaced the glandular parenchyma. A mast cell, M, 1s present. Fig. 5 is the corresponding low power view. 
10. Portion of transverse section of the mammary gland of a rat (M 19.1) twenty-eight days after weaning. Parafin section $5 \mu$ thiok, stained with cresyl violet. $x$ 900. Of the parenchyma there remains only ducts, Du, composed chiefly of closely packed, deeply staining cells in a syncytial mass of cytoplasm. A few atrophic cells, with pyonotic nuclei, Py, are found in the neighborhood of the duets. The fat cells, F.C., of the stroma have almost entirely replaced the parenchyma. Fig. I corresponds well to a low pover view of this section. 


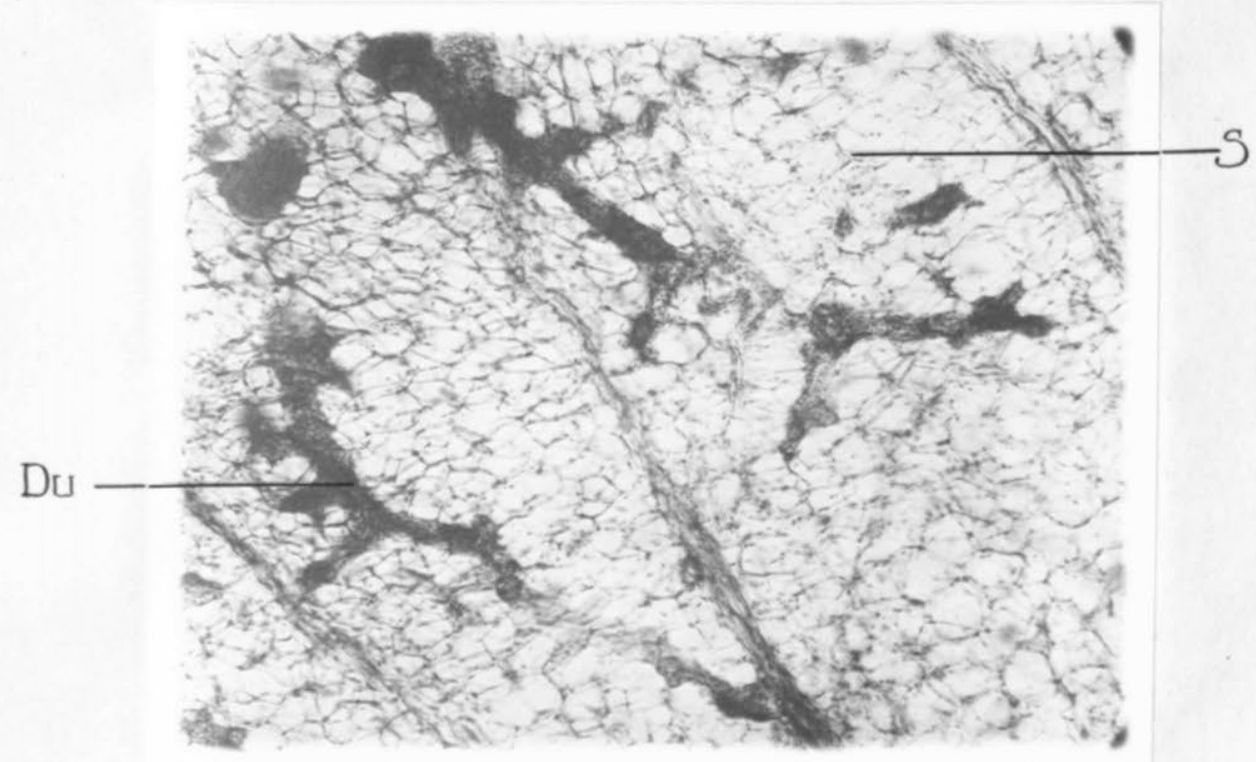

Fig. 1



Fig. 2 


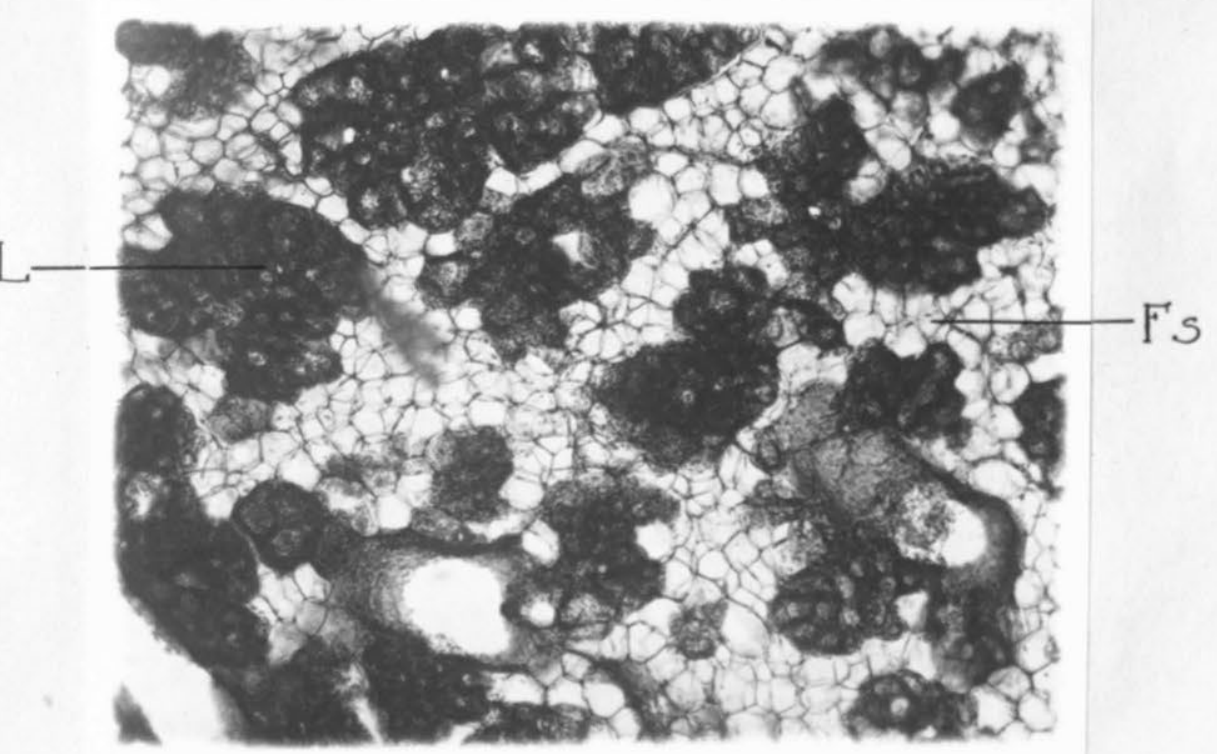

Fig. 3

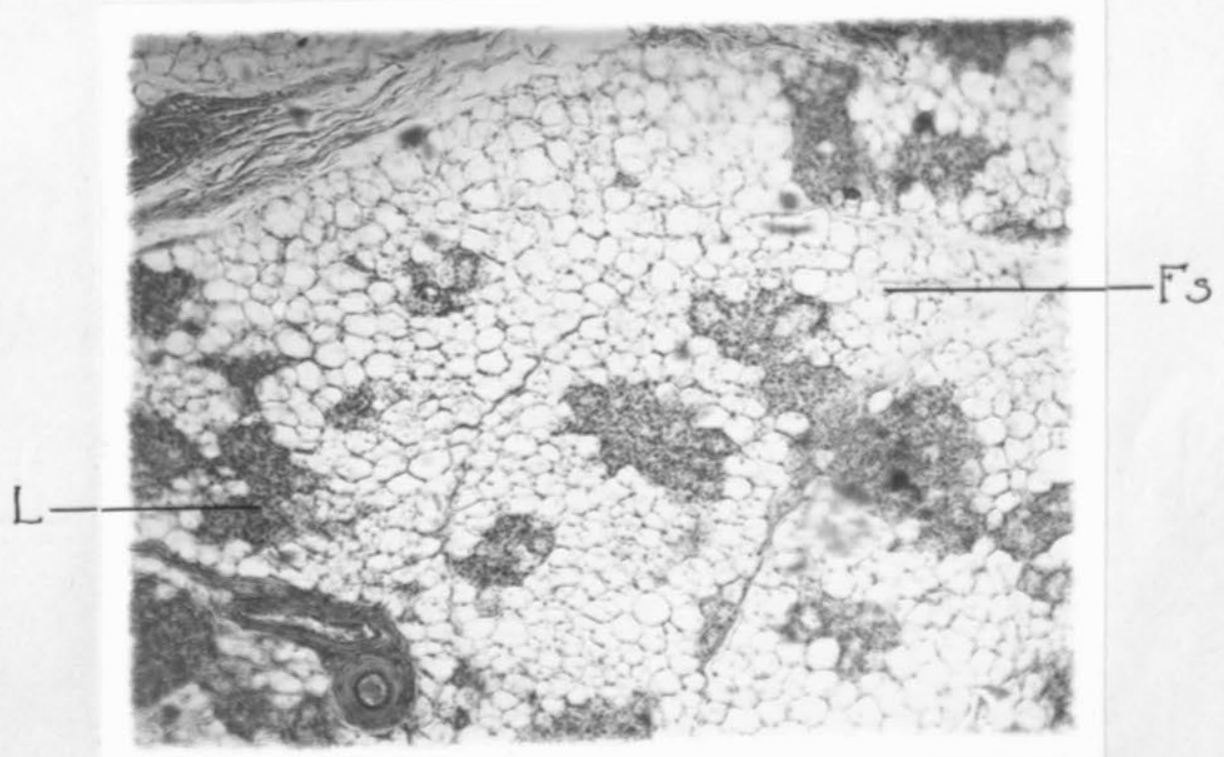

Fig. 4 


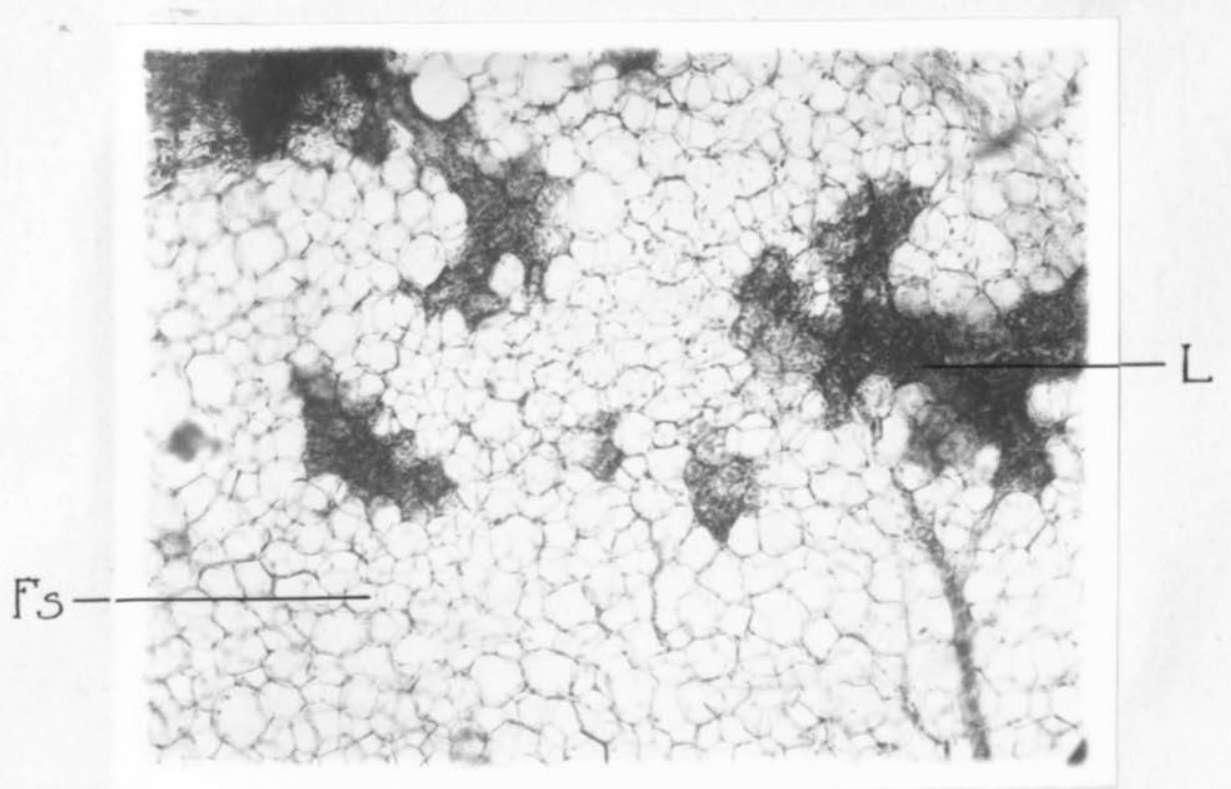

Fig. 5 


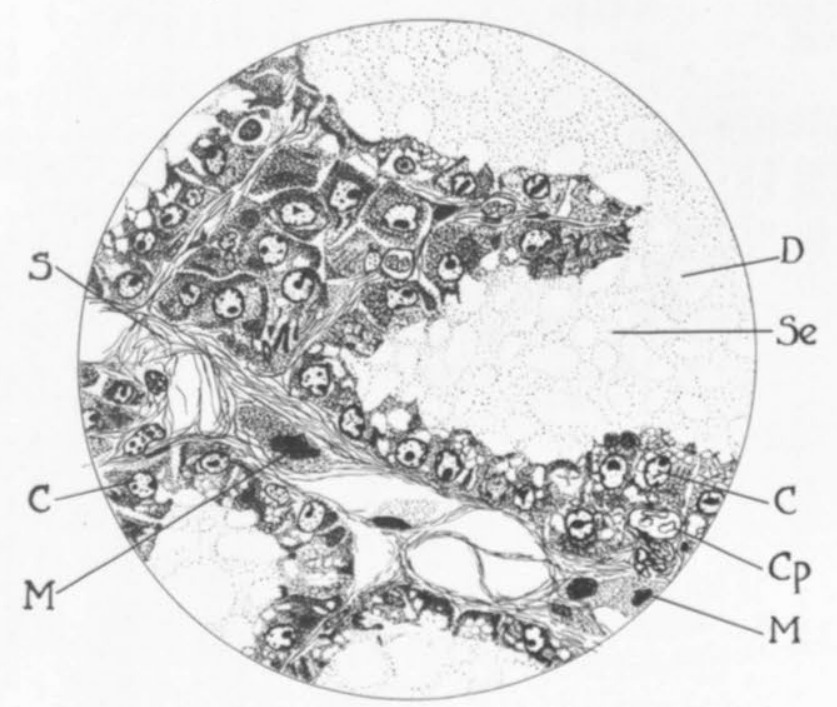

Fig 7

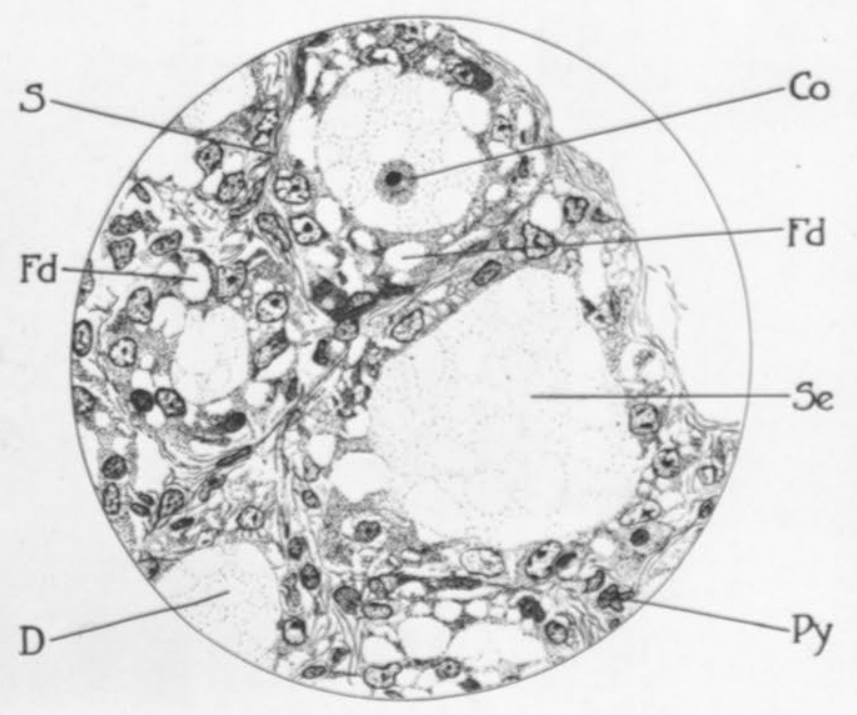

Fìg. 8 


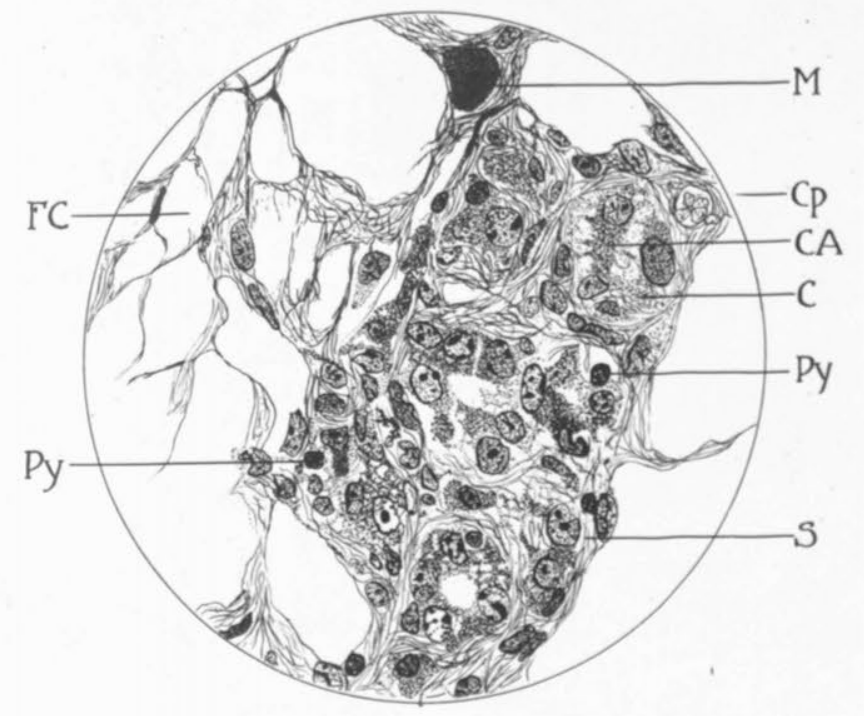

Fìg. 9

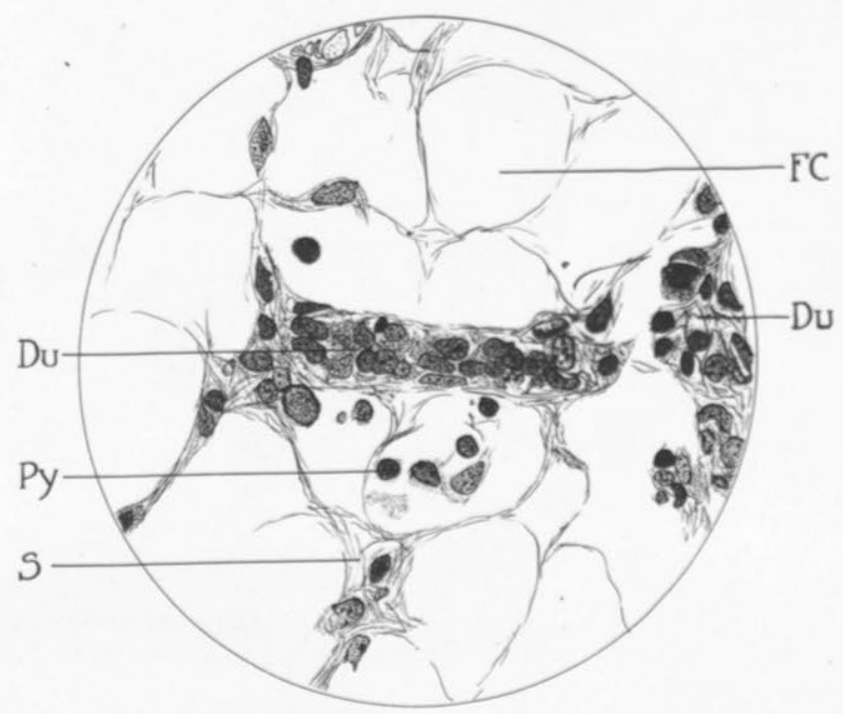

Fis. 10 